\title{
Covid-19 as a Driver Towards Technology Shift: A Focus on Kenya
}

\author{
Benard Muma* \\ Department of Management Science and Technology, Technical University of Kenya \\ P.O. Box 52428 Nairobi Kenya \\ Elyjoy Micheni \\ Department of Management Science and Technology, Technical University of Kenya \\ P.O. Box 52428 Nairobi Kenya \\ Caroline Mundia \\ 3Department of Accounting, Finance and Management Science, Egerton University \\ P.O. Box 13357 Nakuru, Kenya
}

\begin{abstract}
Covid-19 pandemic has had severe effects in economies, businesses and livelihoods. In fact, the pandemic has significantly slowed down all economies with World Health Organization (WHO) projecting that global trade may reduce by between $13 \%$ and $32 \%$ in 2020 . In Kenya, service sector is the most hit sector, with learning institutions suspending physical learning, close to $80 \%$ of hotels suspending operations and small scale service providers leaning operations. However, this study is focused on the positive side of the pandemic. The paper documents technology shifts observed in Kenya during Covid-19 pandemic and identify, empirically, the operational benefits that could possibly be realized through such technologies. The study establishes that while Covid-19 had disastrous effects on businesses and individuals, the pandemic has pushed Kenyans and Kenyan organizations towards technology adoption as witnessed through technology shift during the period. This study serves as preliminary review. Its findings inform a full study that will focus on technology adoption throughout the Covid-19 pandemic. Keywords: Covid -19, Technology Shift, Operational Advantages
\end{abstract}

DOI: $10.7176 / \mathrm{EJBM} / 12-30-05$

Publication date:October $31^{\text {st }} 2020$

\section{Introduction}

Since the first case of Covid 19 was reported in late 2019, literally all areas of life have changed. The United Nations Department of Economic and Social Affairs reports that the Covid - 19 pandemic has had very adverse social and economic impact, especially due to the limited movement resulting from movement restrictions and supply chain disruptions, reduced employments, reduced business operations and trade and increased xenophobia resulting from stigma (United Nations, 2020). Similarly, there has been major supply chain disruption leading to significant reduction in foreign trade and global trade in general (World Trade Organization, 2020). In most countries, in response to recommendations by World Health Organization to minimize physical human interactions among other measures, the governments have had to close down learning institutions, places of worship and suspension of all forms of public gatherings. In severe cases, some countries have resorted to total lockdown.

In Kenya, since the initial cases of Covid - 19 were reported in March 2020, the government has since taken various precautionary measures including; suspension of learning in all learning institutions in Kenya, suspension of all passenger flights into and out of the country, suspension of court hearings and suspension of all public gatherings, including places of worship, social joints, rallies and all other social events. To ensure public service delivery and business continuation under the numerous suspensions, the government issued directive that where possible employees are allowed to work from home. There is in place a curfew between $7 \mathrm{pm}$ and 5 am and intercounty movement restrictions for Nairobi, Mombasa, Kilifi, Kwale and Mandera Counties. The government has put into place stringent guidelines for public transport and businesses that are still able to operate. In addition, the government of Kenya has issued general public health directives and guidelines to be abided by in public places such as wearing of face masks, maintaining social distancing and maintaining personal hygiene (Government of Kenya, 2020). To ensure life continues amidst the stringent business and social environments, significant technology shift has been witnessed, literally in all areas.

\section{Technology Shift}

Technological shifts are sudden changes in technology adoption and use that occur in the environment as a result of innovations or sudden need for technology change (United Nations Commission on Science and Technology for Development, 2018). A number of studies have been conducted to establish the role between technology shifts in business and personal environment. Chairoel, Widyarto and Pujani (2015) established that adoption of 
appropriate technology is associated with operational benefits such as; cost reduction, enhanced productivity and in return improved profit. They further established that technological adoption may be stimulated through disruptions within and external to the business. Adoption of modern technology in manufacturing operations is associated with manufacturing efficiency which in turn leads to improved manufacturing performance (Anjum, 2018). Modern information and communication technology (ICT) such as management and enterprise information systems leads to labor and capital productivity and in return more efficient business and institutional operations. Similarly, adoption of modern ICT enhances communication and stimulates e-commerce (Jameel, Abdul-Karem, \& Mahmood, 2017).

Empirical literature indicates that technology in education environment is inevitable if progressive learning is to be achieved. Study by Valentina, Ramirez and Grandon (2019) revealed that use of in classroom, especially basic education enhances integration and makes learning more practical and interesting to learners. Technology adoption ensures continuity in learning as learners can access learning materials remotely from homes. It enhances innovations through research and online modeling and experiments. Modern technology facilitates administration and students issues management (Abrahams, 2010). Technology adoption is transforming the retail sector. Small and medium businesses are increasingly adopting technology in various areas of their supply chain, including marketing and reverse logistics. Through modern ICT, retail firms are increasingly relying on the internet to market and sell their products (Romero \& Martínez-Román, 2015). Large scale firms are finding it more predictive and cost effective to sell online and deliver to customers as opposed to waiting for customers to come purchase from the stores. This is particularly stimulated by the fact that customers are increasingly moving to online shopping (Chadwick, Doherty, \& Hart, 2000).

While existing literature reveals that adoption of modern technology is associated with operational benefits, adoption of modern technology, especially among small businesses is still relatively low. Most small businesses, due to lack of economies of scale find it uneconomical to incur the high costs associated with modern technologies (Adnan \& Hogue, 2017). Technology change comes with changes in the business internal structure and sometimes culture, sometimes small businesses show low acceptance levels to such changes (Prause, 2019). Amidst challenges experienced by businesses, owing to the operational benefits suggested empirically, businesses should strive to adopt modern technologies in internal operations.

\section{Research Methodology}

This was an exploratory study aimed at documenting the technological paradigm shifts observed in Kenya as a result of Covid-19 pandemic. The research data was collected through observation, interviews and through reference to published reports by the government, media houses and other organizations. Data collection was done for a period of three months; between March 2020 and July 2020. The study deliberately adopted very simple methodology and discussion language. The simple analysis and discussion makes the report understandable to the wider general public. While the findings could stimulate further study in areas of technology adoption and operational benefits, the aim of the study is that the reader appreciates the role of technology in current business and social environment, especially in enhancing virtual engagements and facilitating businesses operations in Kenya and beyond. The findings are aimed at encouraging Kenyans in general to consider adoption of modern technologies moving forward.

\section{Discussion}

This section presents technology shifts observed in Kenya during the Covid-19 pandemic. The findings are presented based on area of adoption.

\subsection{Technological Shift in Education}

Kenyan educational system has predominantly been done physically, with learning taking place through physical interactions between teachers/trainers/lecturers and learners in physical classrooms. While the Kenyan Government rolled out digital learning program for primary schools in 2013, the program is largely still at pilot phase, with many schools in Kenya, especially in the rural areas still offering education through face to face interactions. In secondary schools and middle level colleges, learning is generally through face-to-face interactions and there has been no dedicated effort towards digital/online learning in secondary schools. While most Kenyan universities have been offering online programs even before the Covid-19 pandemic, the approach has been limited to social sciences, information technology and media based programs. Kenyan universities have been offering close to 98 percent of their programs through face to face interactions in a physical classroom.

Since the government suspended physical learning on March, $15^{\text {th }} 2020$, the education sector in Kenya has seen tremendous technological shift. In addition, there are numerous online platforms where pupils can learn comfortably from home. Esoma-Ke for instance is a platform that integrates the current competency based curriculum with the old curriculum and offers learning solutions all the way from pre-primary to secondary education. Kytabu Africa and Ubongo Kids among others also offer online platforms where kids can now learn 
from home. Some schools with digital capacity such as Makini are relying on digital learning through video conferencing, Google classroom, purple mash and virtual classrooms where pupils attend classes using smart phones, tablets or computers.

Schools in urban areas are relying on WhatsApp and e-mails to send class work to pupils who then do them at home under guidance of parents or guardians. Schools in rural and urban informal settlements are majorly relying on radio and television sets to learn through radio or television learning programs. In addition, through communication tools such as Skype, Zoom, Emails and WhatApp, it is much easier to schedule meetings with pupils or parents than before. Similarly, school administrative and board meetings are conducted through video conferencing through Skype and Zoom. Some publishers have also developed e-learning platforms that learners can access remotely through the websites (Longhorn Publishers, 2020).

In the institutions of higher learning, online classes are becoming normality. In fact, according to The Association of African Universities (2020), online learning is an approach that every university in Africa must adopt during the Covid-19 pandemic. Since suspension of physical classes in March, Universities in Kenya have embarked on building capacity to be in a position to offer online classes. Most universities in Kenya are in the process of training their academic staff on online delivery of lectures through Kenya Education Network. For instance, Egerton University and The Technical University of Kenya are currently undertaking such trainings. Learning is increasingly heading online through Skype, Zoom, BlueJeans, WhatsApp, Google Meet, Hangouts and e-mail.

For post graduate studies, some universities such as University of Nairobi and United States International University have rolled out online platforms where students can attend online seminars and even present/defend research proposals and findings online and even have theses examined online (University of Nairobi, 2020). In addition, universities are increasingly inviting students, especially taking post graduate studies to attend webinar to share on contemporary topics. To facilitate online learning, some universities have partnered with telecommunication firms in program dubbed 'Remote learning Mobile Data Bundle Subsidy' to subsidize cost of accessing classes online (Muchiri \& Odhiambo , 2020). In order to enhance research, most universities have extended their portals and now allow students to access library materials remotely from homes using Virtual Private Network or Remotex (University of Nairobi, 2020).

Observations made from the study are that most learning institutions with adequate capacity are increasingly training staff on modern learning tools. It is evident that for some institutions, especially middle and higher education learning institution, this was a transition point. For such institutions, online classes have to be incorporated in the normal institutional programs moving forward. For management, adoption of modern conferencing technology is an innovation that must be fully adopted owing to convenience and efficiency it is associated with. A part from learning, universities are also increasing embracing technology other university operations. in students' admission and graduation. University of Nairobi and Mount Kenya University for instance have put into place through the portals capabilities to process student's admissions online. Egerton University held a virtual graduation in July with University of Nairobi and Kenyatta University planning to have virtual graduations too. Didan Kimathi University of Agriculture and Technology had put into a place an online clearing system to clear students who have graduated from the university.

\subsection{Technological Shift in Business Operations}

While in the past, Kenyan industrial and office environment was largely human dominated, the emergence of Covid-19 pandemic has seen many organizations adopt lean physical workforce and relying information and communications technology to have employees work remotely from home. In response to the directive by government to allow employees work from home, some organizations, especially in the service industry have where possible allowed staff to work and deliver online through dedicated portals. In all government offices, only staff working in critical functions still physically report to the offices.

In the private sector, despite majority of firms being skeptical about allowing employees to work from home, a few firms have also allowed staff to work from home. For instance, Safaricom, the largest telecommunication firm in Kenya has allowed 95\% of its staff to be working from home, ensuring collaboration and team work through Microsoft Teams, WebEx, Yammer \& Cisco Jabber (The East Africa, 2020). Nation Media group has allowed some of its staff to work from home through VPN. The media house has taken advantages of communication tools like E-mail connectivity and Skype-for-business to enhance remote communication and meetings. In fact, Nation Media Group even developed a working from home guide that can be adopted by other organizations (Nation Media Group, 2020).

Generally, it was observed from the analysis in this study that most businesses, are either relaxed or do not have capacity to adopt the current information and communications technology. It was evident that, while Kenyan firms would have wished to have staff work remotely from home, majority of the firms do not have prior exposure to modern tools of communication and conferencing such as Zoom and Skype. In addition most of the businesses do not have information systems infrastructure that can safely allow remote access. Most businesses in Kenya 
therefore still do not have capacity to allow employees work from home. The firms however indicated willingness to have employees work from home and are keen on finding out if such move would lead to any operational benefits.

\subsection{Technology Shift in Business Transactions}

Kenyan business transactions have been predominantly based on physical money transfer, especially for small scale traders and open air markets. With emergence of Covid-19 pandemic, and directive by The Central Bank of Kenya that where possible, cashless transactions are used (The Central Bank of Kenya, 2020), there has been significant transition from cash based to online transactions. In a bid to minimize transmission of Covid-19 diseases, businesses are encouraging customers to pay through cashless platforms such as debit cards and mobile money (Ngweno, 2020). To further encourage cashless transactions, banking and mobile money service providers have zero rates payment transactions, especially for small amounts of money. Safaricom, the leading mobile money transfer company increased daily M-PESA transaction limits from to Kshs.70, 000 to Kshs.150, 000 and user transaction amounts from Kshs.140, 000 to Kshs.300, 000 in MPESA wallets.

In the public transport sector, in a bid to enhance cashless transactions, Safaricom partnered with city shuttling companies such as City Star Shuttle to facilitate fare payment through MPESA and the strategy is slowly getting acceptance (Daily Nation, 2020). A good number of motor cycle (bodaboda) operators in major towns, especially Nairobi and Mombasa were observed to encourage customers to pay through MPESA. The open air market vendors and small businesses operators have not been left behind. Most traders now allow payment through mobile money as an option with few traders considering mobile money the only payment option. In this study, few cases were identified in major towns in Nairobi, Mombasa and Nakuru where traders do not accept cash from customers.

From study findings, while a few traders reported fears associated with cashless transactions such as MPESA transactions reversals by certain customers and withdrawal and transfer costs, the traders expressed confidence that cashless transactions are faster, safer and secure and easily auditable. Actually, majority of traders who used cashless transactions expressed intention to use cashless transactions even post Covid-19 pandemic.

\subsection{Technology Shift in Marketing}

Emergence of Covid-19 has seen Kenyans, especially urban dwellers, with middle and high income increasingly preferring to shop online. Consequently, online shops such as Jumia, Alibaba, Kilimall, Pataway among others are gaining popularity among Kenyans. Infact, Jumia has widened its market target to the low income, densely populated areas that are deemed to be more vulnerable to Covid-19 through their 'OkoaJamiiFreshi' package. OkoaJamiiFreshi offers as a package; $3 \mathrm{kgs}$ of potatoes, $2 \mathrm{kgs}$ of tomatoes, $1 \mathrm{~kg}$ of onions, $2 \mathrm{kgs}$ of maize flour, 2 packets of $500 \mathrm{ml}$ of fresh milk, $500 \mathrm{~g}$ of sugar and $250 \mathrm{ml}$ of cooking oil at Kshs.1,135 (Jumia, 2020). Online shops have increased variety of products as well as enhanced capacity to deliver so as to meet growing customer needs during the Covid-19 pandemic. Online firms have increased variety of product to incorporate simple groceries that were eventually being bought within the areas of residences. For critical service such as medicine, Kenyans are able to access the critical medicines even during curfew hours through online medicine delivery shops such as Mydawa, Dawa Swift and PharmaShop.

Observations made from this study shows that only few Kenyans in middle and high income class were sparingly using online shopping. In addition, online shopping was mainly for items either not locally available, electronics, fashion related and cosmetics. Since the outbreak of Covid-19 however, online shopping is gaining significant preference, including in areas outside Nairobi. Those with online shopping experience are confident that online shopping is convenient and safe especially during the Covid-19 pandemic when people prefer to stay at home. However, online shoppers raise concern of unpredictable delivery times, higher costs and occasional mismatch between an order and delivery. Generally, there is a feeling that online shopping is the way to go, especially during such Covid-19.

\subsection{Technology Shift in Social and Religious Events}

Humans are generally social and religious. Kenyans in particular are as so social and somewhat religious for that matter. In a bid to contain the Covid -19 disease, the government banned all public gatherings, including social and religious gatherings. While such bans have significantly affected social and religious norms of physical gatherings, there has been significant technological response to ensure life continues. Churches have resorted to live streaming of services through online platforms, television sets and radios (Daily Nation, 2020). Live streaming of social events such as weddings, birthday parties and burials are increasingly becoming normal. Arguably, this is one area that technology has come up so strongly and has gained significant technological acceptance (The British Broadcasting Corporation, 2020).

From the study outcomes, it is concluded that there has been significant technological paradigm shift during the Covid-19 pandemic in Kenya. Firms and people have tried to ensure continuity through technology adoption. Through such adoption, Kenyan firms and citizens continue to appreciate the role of technology, especially 
information and communication technology in economic and social aspects in equal measures. The study also concludes that Kenyans in general are increasingly accepting advanced technology, an indication that soon there may be serious technology disruptions in Kenyans business and social environment. Lastly, the study concludes that firms need to invest in information and communication technology, train and expose staff to modern technologies. This is particularly important as indication in preparing the firms for a more progressive economy post Covid-19.

\section{Conclusions}

From the study outcomes, it is concluded that there has been significant technological paradigm shift during the Covid-19 pandemic in Kenya. Firms and people have tried to ensure continuity through technology adoption. Through such adoption, Kenyan firms and citizens continue to appreciate the role of technology, especially information and communication technology in economic and social aspects in equal measures. The study also concludes that Kenyans in general are increasingly accepting advanced technology, an indication that soon there may be serious technology disruptions in Kenyans business and social environment. Lastly, the study concludes that firms need to invest in information and communication technology, train and expose staff to modern technologies. This is particularly important as indication in preparing the firms for a more progressive economy post Covid-19. The findings in this study inform on a longitudinal study that will focus on the entire period of Covid-19.

\section{References}

1] Abrahams, D. (2010). Technology Adoption in Higher Education: A Framework for Identifying and Prioritising Issues and Barriers to Adoption of Instructional Technology. Journal of Applied Research in Higher Education, 2(2), 33-49.

2] Adnan, A., \& Hogue, R. (2017). Factors Affecting the adoption of Information and Communication Technology in Small and Medium Enterprises: a perspective from Rural Saudi Arabia. Information Technology for Development, 25(4), 715-738.

3] Anjum, A. (2018). Impact of Technology Adoption on the Performance of Small and Medium Enterprises in India. The Journal of Social Sciences Research, 5; 857-867.

4] Chadwick, F., Doherty, N., \& Hart, C. (2000). Retailer Aoption of the Internet - Implications for Retail Marketing. European Journal of Marketing, 34(8), 954- 974.

5] Chairoel, L., Widyarto, S., \& Pujani, V. (2015). ICT adoption in affecting organizational performance among Indonesian SMEs. The International Technology Management Review, 5(2), 82-93.

6] Daily Nation. (2020, March 22). Daily Nation. Retrieved May 3, 2020, from Nation Media Group: https://www.nation.co.ke/news/New-dawn-for-Sunday-church-services-Covid-19/1056-5499938$157 \mathrm{~s} 9 \mathrm{hd} /$ index.html

7] Daily Nation. (2020, March 23). How to pay Bus Fare by M-Pesa in the Wake of Covid-19. Retrieved May 2, 2020, from The Nation Madia Group: https://www.nation.co.ke/business/How-to-pay-bus-fare-by-MPesa-in-the-wake-of-Covid-19/996-5501638-tjo5jn/index.html

8] Dell, S., \& Sawahel , W. (2020). African Universities urged to put Classes Online Urgently. Accra: The Association of African Universities.

9] Government of Kenya. (2020). Stop the Spread of Covid-19. Nairobi: Government of Kenya.

10] Jameel, A., Abdul-Karem, M., \& Mahmood, N. (2017). A Review of the Impact of ICT on Business Firms. International Journal of Latest Engineering and Management Research, 2(1), 13-19.

11] Jumia. (2020). Okoa Jamii Freshi. Retrieved May 2, 2020, from Jumia: https://www.jumia.co.ke/twiga-okoajamii-freshi-28921373.html

12] Longhorn Publishers. (2020, March 2020). Longhorn eLearning Platform. Retrieved May 2nd, 2020, from Longhorn Publishers: https://elearning.longhornpublishers.com/

13] Muchiri, T., \& Odhiambo, B. (2020). USIU-Africa Partners with Safaricom, Telkom to Provide Subsidized e-learning Tariffs to Students and Faculty. Nairobi: United States International University-Africa.

14] Nation Media Group. (2020, April 4). Daily Nation. Retrieved May 2, 2020, from Nation Media Group: https://www.nation.co.ke/news/The-future-of-work-post-Covid-19/1056-5513888-xrju3yz/index.html

15] Ngweno, A. (2020, March 23). Digital Financial Transfers can Supercharge the Response to COVID-19. Retrieved May 2, 2020, from BFA Global: https://bfaglobal.com/insight-type/blogs/digital-financialtransfers-can-supercharge-the-response-to-covid-19/

16] Prause, M. (2019). Challenges of Industry 4.0 Technology Adoption for SMEs: The Case of Japan. Sustainability, 1-13.

17] Romero, I., \& Martínez-Román, J. (2015). Determinants of Technology Adoption in the Retail Trade Industry - the Case of SMEs in Spain. Amfiteatru Economic, 17(39):646-660.

18] The British Broadcasting Corporation. (2020, April 13). BBC. Retrieved May 3, 2020, from Kenyan 
Weddings, Births and Deaths in the Age of Covid-19: https://www.bbc.com/news/world-africa-52220771

19] The Central Bank of Kenya. (2020, March 24). National Emergency Measures to Mitigate the Adverse Effects on the Banking Sector from the Coronavirus Pandemic. Retrieved May 2, 2020, from Central Bank of Kenya: https://www.centralbank.go.ke/uploads/press_releases/2088534699_Press\%20Release\%20-\%20Banking\%2 0Sector\%20Additional\%20Measures.pdf

20] The East Africa. (2020, March 2020). Technology Saves the Day as Kenyan Firms Send Staff to Work from Home. Retrieved May 2, 2020, from The East Africa: https://www.theeastafrican.co.ke/news/ea/Kenyanfirms-send-staff-to-work-from-home/4552908-5499786-10laiaz/index.html

21] United Nations. (2020). The Social Impact of COVID-19. New York: United Nations.

22] United Nations Commission on Science and Technology for Development. (2018). The impact of Rapid Technological Change on Sustainable Development. Vienna: United Nations Commission on Science and Technology for Development.

23] University of Nairobi. (2020, April 10). Library Remote Access Options. Retrieved April 30, 2020, from University of Nairobi: https://uonlibrary.uonbi.ac.ke/node/395349

24] University of Nairobi. (2020, April 6). Status of Learning at uoN during the Covid-19 Lockdown. Retrieved April 30, 2020, from Univeristy of Nairobi: https://www.uonbi.ac.ke/news/status-learning-uon-during-covid19-lockdown

25] Valentina, A., Remirez, P., \& Gradon, E. (2019). Innovativeness and Factors that Affect the Information Technology Adoption in the Classroom by Primary Teachers in Chile. Informatics in Education, 18(1):165181.

26] World Health Organization. (2020). Key Planning Recommendations for Mass Gatherings in the Context of the Current COVID-19 Outbreak. UK: World Health Organization.

27] World Trade Organization. (2020). Trade Set to Plunge as COVID-19 Pandemic Upends Global Economy. Geneva: World Trade Organization. 